\title{
Focal macular photopic negative response in patients with optic neuritis
}

\begin{abstract}
Purpose To investigate, by focal macular electroretinography (ERG), the change of photopic negative response (PhNR) in the recovery of visual function in patients with optic neuritis.

Methods Focal macular ERG was recorded from nine patients with acute optic neuritis (38.6 \pm 10.2 years). The photostimulator device projected $15^{\circ}$ visual angle spotlight onto the macula. Focal macular ERG recording was performed at the onset and at 1 month and 6 months after the onset of optic neuritis. The results were compared between each recording for seven of the patients.

Results All patients decreased in the vision below 20/100 and had central scotoma. Vision improved more than 20/20 within 1 month and full-visual field recovered within 6 months after the onset in all patients. The amplitude of the a-wave, b-wave, and PhNR of focal macular ERG at the onset was significantly attenuated in eyes with optic neuritis $(66.8 \pm 15.5,65.8 \pm 17.7$, and $65.2 \pm 14.4 \%$ of normal control, respectively). The amplitude of the a-wave and b-wave increased gradually after steroid pulse therapy. The increase in a-wave amplitude was significant at 6 months $(P=0.046)$, whereas the PhNR amplitude did not show any significant change over 6 months after the onset of optic neuritis.

Conclusions Our results suggest that inflammation at the onset of optic neuritis leads to functional deficits that extend to at least the inner nuclear layers of the retina, and that all but the ganglion cell layers of retina recover.
\end{abstract}

Eye (2011) 25, 358-364; doi:10.1038/eye.2010.205; published online 7 January 2011 Accepted in revised form: 29 October 2010 Published online: 7 January 2011
Keywords: focal electroretinogram; photopic negative response; optic neuritis; macula
H Nakamura, K Miyamoto, S Yokota, K Ogino and $\mathrm{N}$ Yoshimura

\section{Introduction}

The photopic negative response (PhNR) is a slow, negative-going wave of the photopic electroretinogram (ERG) that appears immediately after the b-wave. In experiments in primate glaucoma, the amplitude of the PhNR was found to be reduced after the action potentials of the retinal ganglion cell (RGC) that are blocked by an intravitreal injection of tetradotoxin. ${ }^{1,2}$ A number of studies suggest that the PhNR in the photopic ERG originates primarily from activity of RGCs and their axons. ${ }^{1-9}$ In clinical studies using full-field ERGs, the PhNR amplitude was reduced in various diseases that involves RGC damage - for example, glaucoma, ${ }^{3-5}$ retinal vascular disease, ${ }^{6,7}$ and optic nerve diseases. ${ }^{8-10}$ Several researchers measured PhNR by using focal macular ERG in humans and monkeys. ${ }^{11-15}$ Focal macular PhNR detected early glaucoma with higher sensitivity and specificity than full-field PhNR. ${ }^{5,15}$

Most patients with acute idiopathic demyelinating optic neuritis have good visual acuity. However, 5-10\% of patients recover poorly, ${ }^{16}$ and many more patients notice residual qualitative deficits. ${ }^{17}$ In $20 \%$ of patients, optic neuritis is the first manifestation of multiple sclerosis, ${ }^{18}$ and in $38 \%$ multiple sclerosis develops within 10 years. ${ }^{19-21}$ Although optic neuritis is used to study demyelination, the mechanisms of damage and repair in this disease are not completely understood. Moreover, there are no effective treatments to improve vision for people who have this condition. Understanding the mechanisms underlying damage and repair in demyelinating diseases of the central nervous system is important to devise better treatments. A previous histopathological study showed that optic nerve axonal count correlated with retinal nerve fiber layer (RNFL) thickness. ${ }^{22}$ Moreover, optic atrophy and RNFL thinning have been 
noted in many patients with multiple sclerosis. ${ }^{23,24}$ Therefore, RNFL thickness, as measured by optical coherence tomography, has been suggested as an indicator of axonal loss in the optic nerve. ${ }^{25,26}$ Furthermore, recent studies that used ultrahighresolution optical coherence tomography suggest that retinal ganglion cell loss in the macula occurs concomitantly with RNFL thinning. ${ }^{27-29}$ Burkholder et $a l^{30}$ showed that peripapillary RNFL thinning is associated with reduction in macular volume among eyes of patients with multiple sclerosis and with or without optic neuritis.

A number of studies have been done on recording $\mathrm{PhNR}$ from the macula in patients and monkeys with optic nerve disease, including glaucoma and optic nerve atrophy, ${ }^{2,11,12,15}$ however, to our knowledge, the change in the focal macular PhNR during vision recovery from optic neuritis has not been investigated yet. This is important to gain a better understanding of the functional mechanisms during vision recovery, and the prediction of visual prognosis of optic neuritis. In this study, we investigated the change of focal macular ERG at the onset and at 1 and 6 months after the onset of optic neuritis. We also investigated the functional mechanisms during vision recovery from optic neuritis.

\section{Patients and methods}

\section{Subjects}

Nine subjects with clinically diagnosed acute unilateral optic neuritis of first onset (5 males and 4 females, mean age $38.6 \pm 10.2$ years, range $25-55$ years) were examined between December 2007 and November 2009 at the Neuro-ophthalmology Service of Kyoto University Hospital (Kyoto, Japan). All patients were treated with systemic corticosteroids, and had improved best-corrected visual acuity (that is, equal to or better than 20/20 in the Snellen equivalent) and visual field but not optic nerve atrophy.

Optic neuritis was diagnosed by a consultant neuroophthalmologist and was based on clinical findings such as unilateral visual loss, pain on eye movement, relative afferent papillary defect, and color vision deficiency. The patients underwent comprehensive ophthalmological examination including Snellen visual acuity, slitlamp biomicroscopy, indirect ophthalmoscopy, and kinetic or static visual field perimetry. Individuals with a neurological disease or a history of diabetes or corticosteroid use were excluded. Other exclusion criteria were eyes with any type of retinal pathology, opaque media, or a history of retinal laser procedure or surgery. All patients received intravenous methylprednisolone ( $1 \mathrm{~g}$ per day for 3 days) followed by an 11-day oral prednisolone taper.
The procedures used in this study conformed to the tenets of the Declaration of Helsinki and the study was approved by the Institutional Review Board and Ethics Committee of the Kyoto University Graduate School of Medicine. After a full explanation of the nature and possible consequences of the study, informed consent was obtained from each individual who served as a subject.

\section{Focal macular ERG recording}

The stimulation system for obtaining focal photopic ERGs was integrated into the infrared fundus camera (Mayo Co., Nagoya, Japan); this system was originally developed by Miyake et al. ${ }^{31-36}$ We recorded focal photopic ERGs by projecting a $15^{\circ}$ visual angle circular spotlight onto the macula (Figure 1c). During ERG recordings, all subjects were instructed to fixate on the point at the center of the visual field, and whether the center of the stimulus spot remained on the fovea was monitored by the infrared fundus image. The luminance values of the white stimulus light and white background illumination were 181.5 and $6.9 \mathrm{~cd} / \mathrm{m}^{2}$, respectively.

The stimulus duration was $150 \mathrm{~ms}$.

ERG recording was performed after the pupils have been maximally dilated with topical applications of $0.5 \%$ tropicamide and $0.5 \%$ phenylephrine. The BurianAllen bipolar contact lens electrode (Hansen Ophthalmic Laboratories, Iowa City, IA, USA) was inserted into the conjunctival sac. The left ear served as a ground. Focal ERGs were recorded with $2-\mathrm{Hz}$ rectangular stimuli (light on for $150 \mathrm{~ms}$ and light off for $350 \mathrm{~ms}$ ). A total of 200-300 responses were averaged by a signal processor (Neuropack MEB-2204; Nihon Kohden, Tokyo, Japan). The focal ERG response was digitized at $10 \mathrm{kHz}$ with a band-pass filter of $5-500 \mathrm{~Hz}$.

Focal macular ERG recording was performed at the onset and at 1 and 6 months after the onset of optic neuritis. The amplitude and implicit times of the a-wave, b-wave, and PhNR were measured in each recording. The a-wave and PhNR amplitude was measured from the baseline to the peak of the a-wave and $\mathrm{PhNR}$, respectively. The b-wave amplitude was measured from the trough of the a-wave to the peak of the b-wave (Figure 1a). Results of the focal ERG responses were normalized by values obtained from 17 age-matched normal controls.

\section{Statistical analyses}

To compare focal macular ERGs between patients with optic neuritis and normal controls, unpaired $t$-test was used. To analyze significant differences in focal macular ERG among the onset and at 1 and 6 months after the onset of disease, one-way analysis of variance was 
a



b

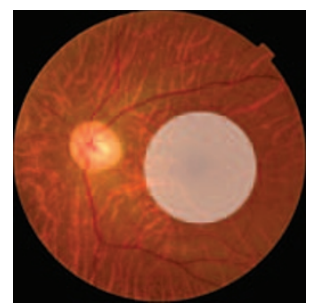

Central macula
C

eyes with optic neuritis

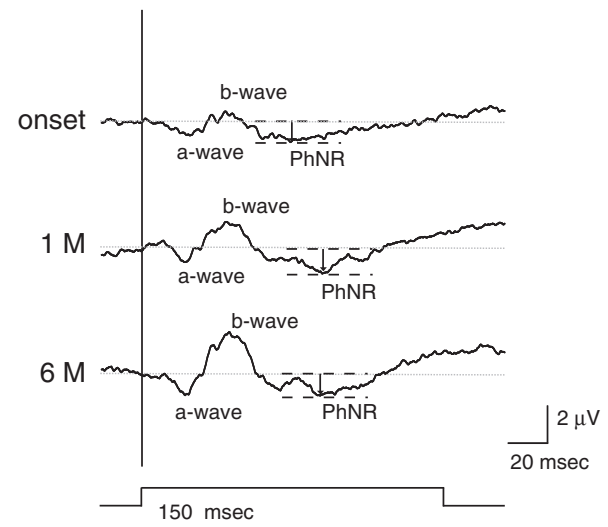

Figure 1 (a) A representative normal example to show focal macular PhNR recording. (b) Stimulus areas for focal macular PhNR recordings. The $15^{\circ}$ circular stimulus is positioned in the macula. (c) A representative focal macular ERG was recorded from the central macular area at the onset and at 1 month and 6 months after the onset of optic neuritis in the eye of a 47-year-old male.

performed with post hoc Bonferroni correction. Statistical analyses were performed using PASW Stats version 17.0 (SPSS Inc., Chicago, IL, USA). Statistical significance was set at $P<0.05$.

\section{Results}

\section{Visual acuity and visual field}

Visual acuity was worse than $4 / 20$ (mean \pm SD, $0.07 \pm 0.08$, decimal vision) in the onset of optic neuritis. However, visual acuity recovered to $20 / 20$ or better within 1 month of the attack in all patients. All nine patients had a central scotoma in their visual field. They had undergone Goldmann perimetry test and/or Humphrey field analyzer (Carl Zeiss Meditec, Dublin, CA, USA) with the SITA (Swedish Interactive Threshold Algorithm) standard 30-2 program at the onset of optic neuritis and at 6 months after the onset. Four of nine patients, who had Goldman perimetry test, improved their visual field without central scotoma within 6 months. Six of nine patients, who had Humphrey field analyzer with SITA 30-2 program test, improved their visual field within 6 months (mean MD $\pm \mathrm{SD}$ : $-28.52 \pm 5.64$ at the onset; $-1.96 \pm 0.59$ at 6 months).

\section{Representative case}

Representative ERGs recorded from the affected eyes at the onset of optic neuritis in patient four are shown in Figure 1b. The normalized a-wave, b-wave, and PhNR amplitude of focal macular ERG was significantly reduced in the affected eye $(42.9,30.7$, and $45.5 \%$, respectively). Subsequently, the normalized a-wave and b-wave amplitude of focal macular ERG gradually increased in the affected eye $(42.9,73.6$, and $79.8 \%$ in a-wave, $30.7,61.5$, and $97.8 \%$ in b-wave at onset, at 1 month and 6 months, respectively). On the other hand, the normalized PhNR amplitude did not show any change during 6 months after the onset of optic neuritis in the affected eye $(45.5,50.0$, and $50.0 \%$ at onset, at 1 month and 6 months, respectively). No differences in the peak time of focal macular ERG were observed during the 6-month follow-up period.

\section{Focal macular ERG of the patients with optic neuritis}

Focal macular ERG was significantly attenuated in the affected eyes $(66.8 \pm 15.5,65.8 \pm 17.7$, and $65.2 \pm 14.4 \%$ of the normal control, respectively). The normalized amplitude of the a-wave, b-wave, and PhNR in the nine affected eyes was significantly smaller than that of normal controls $(P<0.001$ in all cases). The normalized peak time of the a-wave, b-wave, and PhNR in the affected eyes was $100.4 \pm 6.0,101.6 \pm 3.5$, and $94.8 \pm 5.3 \%$, respectively. No significant difference was observed in the peak time of the a-wave and b-wave between the affected eyes and normal controls; however, the peak time of PhNR in the affected eyes was significantly earlier than that of normal controls $(P=0.008)$. 
Comparison in focal macular ERG between the onset and at 1 and 6 months after the onset of optic neuritis

We recorded the focal macular ERG of seven eyes of seven patients with optic neuritis at the onset and at 1 and 6 months after the onset of symptoms. We also investigated the change in focal macular ERG at patient follow-up. Although there were no significant differences in the normalized a-wave amplitude between onset and 1 month after onset, and between 1 month and 6 months after onset, the normalized a-wave amplitude significantly increased at 6 months after disease onset $(P=0.046)$. The normalized $b$-wave amplitude gradually increased after steroid pulse therapy. However, the increase in b-wave amplitude did not reach significance. On the other hand, the normalized PhNR amplitude did not show any significant change over 6 months after the onset of optic neuritis. For the normalized peak time, there were no significant differences in the a-wave, b-wave and PhNR between the onset of optic neuritis, and at 1 month and 6 months after treatment (Figure 2).

\section{Discussion}

$\mathrm{PhNR}$ reduction is correlated with the loss of visual field sensitivity in patients with glaucoma. ${ }^{12,15} \mathrm{PhNR}$ is also selectively reduced in eyes with optic nerve atrophy, which is induced by trauma, compression, inflammation, ischemia, or gene mutation. ${ }^{8-10}$ Our results provide additional evidence that focal macular PhNR is immediately and strongly attenuated by the onset of optic neuritis and that PhNR did not improve even after patients were treated with systemic corticosteroids, which resulted to improved visual acuity and visual field but not optic atrophy.

\section{Reduction of focal macular ERG in patients with optic neuritis}

Our results showed that the amplitude of the a-wave, b-wave, and PhNR of focal macular ERG was immediately and significantly reduced at the onset of optic neuritis symptoms. A previous report has shown that PhNR amplitude remained unchanged in the early stages of optic neuropathy and that PhNR was reduced or completely lost as RNFL thinning progressed. ${ }^{9}$

However, they recorded PhNR in patients with optic nerve atrophy by using full-field ERG, which is the summed response from the entire retina. Therefore, full-field ERG is not an ideal tool to assess the function of localized retinal areas. Recent studies have used focal macular ERG to record the PhNR from localized retinal areas. ${ }^{12-15}$ Machida et al ${ }^{12,15}$ suggested that focal PhNR can detect early glaucoma with higher sensitivity and specificity than full-field PhNR. Therefore, the reduction of focal macular PhNR amplitude in patients with optic neuritis suggests that an inner retinal dysfunction of the macula already exists at the onset of symptoms. Inflammation, demyelination and conduction block in the optic nerve occur during the acute phase of the disease. $^{37}$ The finding that the amplitude of the PhNR, a-wave, and b-wave were reduced at the onset stage of optic neuritis indicates that at least the retinal inner


Figure 2 Changes in the mean PhNR amplitude in all seven eyes of seven patients with optic neuritis after disease onset. Each value at onset, 1 month and 6 months is expressed as the normalized amplitude $(a-c)$ and peak time (d-f) in focal macular ERG. Error bars indicate the SEM. 
nuclear layer, or mechanisms for generating ERG signals from the layer are also affected in acute stages of optic neuritis, not just ganglion cellsthe axons of which are from the optic nerve. For the a-wave, amplitude reduction could be post-receptoral as OFF pathway contributes to a-wave, but effects on the photoreceptors cannot be ruled out.

\section{Change in the focal macular PhNR after steroid therapy}

The amplitude of the a-wave and b-wave was significantly reduced at the onset of optic neuritis, but it gradually improved toward the normal range after steroid pulse therapy. On the other hand, PhNR amplitude was significantly reduced at the onset of optic neuritis and did not show any further changes. Gotoh et $a l^{9}$ reported that PhNR amplitude was considerably reduced at 1 month after onset in their study of full-field PhNR in patients with optic nerve disease. Our results are consistent with their report. At the onset of optic neuritis, inflammation, demyelination, and conduction block in the optic nerve occur. ${ }^{38}$ Therefore, the amplitude of the a-wave, b-wave, and PhNR might be reduced at the onset of optic neuritis. However, over subsequent weeks, inflammation resolves and electrical conduction improves, although there is significant evidence for persistent optic nerve demyelination. ${ }^{37,39}$ The improvement in electrical conduction caused an increase in the a-wave and b-wave amplitude in focal macular ERG at 1 and 6 months after the onset of optic neuritis. The remaining reduced amplitude of focal macular PhNR suggests that an inner retinal dysfunction remains in the macula after treatment of optic neuritis.

\section{Comparison with the pattern ERG}

Pattern ERG is known to be correlated with retinal ganglion cell activity. ${ }^{40,41}$ Some researchers recorded pattern ERG for patients with optic neuritis. ${ }^{42-45}$ The positive peak of the pattern ERG is produced by retinal structures that are not myelinized, ${ }^{46}$ whereas the negative component of the pattern ERG is mainly affected in optic nerve diseases if the pattern ERG is abnormal. ${ }^{47}$ Berninger and Heider ${ }^{43}$ showed that the positive component of the pattern ERG (P50) was reduced in all acutely affected eyes in comparison with the fellow eye in acute retrobulbar optic neuritis. In addition, they showed that the amplitude of the positive pattern ERG component increased to normal during recovery of optic neuritis. On the other hand, Plant et $a l^{45}$ observed permanent reduction of the pattern ERG amplitude in some patients during remission of optic neuritis by using the steady-state response, which is dominated by the negative component. Their observations are in accordance with our findings in this study. As for the peak latency for the eyes with optic neuritis in the pattern ERG, Huban $e t a l^{44}$ reported that, although the mean P50 latency did not show significant difference between the affected eyes and the unaffected eyes, the mean N95 latency in the affected eyes was significantly shorter than that in the unaffected eyes. Our result does not conflict with their findings. However, we do not know very well why the peak latency of PhNR in the eyes with optic neuritis was significantly faster than that of normal controls. Further investigation will be made.

In summary, we investigated the change in focal macular ERG at the onset of optic neuritis and after steroid pulse therapy of patients with optic neuritis. We suggested that inflammation at the onset of optic neuritis leads to functional deficits that extend to at least the inner nuclear layers of the retina, and that all but the ganglion cell layers of retina recover. Measurement of focal macular ERG in patients with optic neuritis can be useful to understand the pathological mechanisms of the disease. Moreover, focal macular ERG might have the potential to predict the visual prognosis of the disease. We are required to evaluate many more patients with optic neuritis by using focal macular ERGs and to compare with other clinical findings. Further investigation will be needed.

\section{Summary}

What was known before

- Most patients with acute idiopathic demyelinating optic neuritis have good visual acuity. However, 5-10\% of patients recover poorly, and many more patients notice residual qualitative deficits.

What this study adds

- Inflammation at the onset of optic neuritis leads to functional deficits that extend to at least the inner nuclear layers of the retina, and that all but the ganglion cell layers of retina recover.

\section{Conflict of interest}

The authors declare no conflict of interest.

\section{References}

1 Viswanathan S, Frishman LJ, Robson JG, Harwerth RS, Smith III EL. The photopic negative response of the macaque electroretinogram: reduction by experimental glaucoma. Invest Ophthalmol Vis Sci 1999; 40(6): 1124-1136.

2 Viswanathan S, Frishman LJ, Robson JG. The uniform field and pattern ERG in macaques with experimental glaucoma: removal of spiking activity. Invest Ophthalmol Vis Sci 2000; 41(9): 2797-2810 
3 Viswanathan S, Frishman LJ, Robson JG, Walters JW. The photopic negative response of the flash electroretinogram in primary open angle glaucoma. Invest Ophthalmol Vis Sci 2001; 42(2): 514-522.

4 Drasdo N, Aldebasi YH, Chiti Z, Mortlock KE, Morgan JE, North RV. The S-cone PhNR and pattern ERG in primary open angle glaucoma. Invest Ophthalmol Vis Sci 2001; 42(6): 1266-1272.

5 Machida S, Gotoh Y, Toba Y, Ohtaki A, Kaneko M, Kurosaka D. Correlation between photopic negative response and retinal nerve fiber layer thickness and optic disc topography in glaucomatous eyes. Invest Ophthalmol Vis Sci 2008; 49(5): 2201-2207.

6 Machida S, Gotoh Y, Tanaka M, Tazawa Y. Predominant loss of the photopic negative response in central retinal artery occlusion. Am J Ophthalmol 2004; 137(5): 938-940.

7 Chen $\mathrm{H}, \mathrm{Wu} \mathrm{D}$, Huang S, Yan $\mathrm{H}$. The photopic negative response of the flash electroretinogram in retinal vein occlusion. Doc Ophthalmol 2006; 113(1): 53-59.

8 Rangaswamy NV, Frishman LJ, Dorotheo EU, Schiffman JS, Bahrani HM, Tang RA. Photopic ERGs in patients with optic neuropathies: comparison with primate ERGs after pharmacologic blockade of inner retina. Invest Ophthalmol Vis Sci 2004; 45(10): 3827-3837.

9 Gotoh Y, Machida S, Tazawa Y. Selective loss of the photopic negative response in patients with optic nerve atrophy. Arch Ophthalmol 2004; 122(3): 341-346.

10 Miyata K, Nakamura M, Kondo M, Lin J, Ueno S, Miyake Y et al. Reduction of oscillatory potentials and photopic negative response in patients with autosomal dominant optic atrophy with OPA1 mutations. Invest Ophthalmol Vis Sci 2007; 48(2): 820-824.

11 Colotto A, Falsini B, Salgarello T, Larossi G, Galan ME, Scullica L. Photopic negative response of the human ERG: losses associated with glaucomatous damage. Invest Ophthalmol Vis Sci 2000; 41(8): 2205-2211.

12 Machida S, Toba Y, Ohtaki A, Gotoh Y, Kaneko M, Kurosaka D. Photopic negative response of focal electoretinograms in glaucomatous eyes. Invest Ophthalmol Vis Sci 2008; 49(12): 5636-5644.

13 Kondo M, Kurimoto Y, Sakai T, Koyasu T, Miyata K, Ueno $\mathrm{S}$ et al. Recording focal macular photopic negative response (PhNR) from monkeys. Invest Ophthalmol Vis Sci 2008; 49(8): 3544-3550.

14 Kurimoto Y, Kondo M, Ueno S, Sakai T, Machida S, Terasaki H. Asymmetry of focal macular photopic negative responses (PhNRs) in monkeys. Exp Eye Res 2009; 88(1): 92-98.

15 Machida S, Tamada K, Oikawa T, Yokoyama D, Kaneko M, Kurosaka D. Sensitivity and specificity of photopic negative response of focal electoretinogram to detect glaucomatous eyes. Br J Ophthalmol 2010; 94(2): 202-208.

16 Beck RW, Gal RL, Bhatti MT, Brodsky MC, Buckley EG, Chrousos GA et al. Optic Neuritis Study Group. Visual function more than 10 years after optic neuritis: experience of the optic neuritis treatment trial. Am J Ophthalmol 2004; 137(1): 77-83.

17 Cleary PA, Beck RW, Bourque LB, Backlund JC, Miskala PH. Visual symptoms after optic neuritis. Results from the Optic Neuritis Treatment Trial. J Neuroophthalmol 1997; 17(1): $18-23$.

18 Sørensen TL, Frederiksen JL, Brønnum-Hansen $\mathrm{H}$, Petersen HC. Optic neuritis as onset manifestation of multiple sclerosis: a nationwide, long-term survey. Neurology 1999; 53(3): 473-478.
19 Beck RW, Trobe JD, Moke PS, Gal RL, Xing D, Bhatti MT, et al. Optic Neuritis Study Group. High- and low-risk profiles for the development of multiple sclerosis within 10 years after optic neuritis: experience of the optic neuritis treatment trial. Arch Ophthalmol 2003; 121(7): 944-949.

20 Ghezzi A, Martinelli V, Torri V, Zaffaroni M, Rodegher M, Comi $\mathrm{G}$ et al. Long-term follow-up of isolated optic neuritis: the risk of developing multiple sclerosis, its outcome, and the prognostic role of paraclinical tests. J Neurol 1999; 246(9): 770-775.

21 Rodriguez M, Siva A, Cross SA, O’Brien PC, Kurland LT. Optic neuritis: a population-based study in Olmsted County, Minnesota. Neurology 1995; 45(2): 244-250.

22 Yücel YH, Gupta N, Kalichman MW, Mizisin AP, Hare W, de Souza Lima M et al. Relationship of optic disc topography to optic nerve fiber number in glaucoma. Arch Ophthalmol 1998; 116(4): 493-497.

23 Kerrison JB, Flynn T, Green WR. Retinal pathologic changes in multiple sclerosis. Retina 1994; 14(5): 445-451.

24 Elbøl P, Work K. Retinal nerve fiber layer in multiple sclerosis. Acta Ophthalmol (Copenh) 1990; 68(4): 481-486.

25 Sergott RC, Frohman E, Glanzman R, Al-Sabbagh A, OCT in MS Expert Panel. The role of optical coherence tomography in multiple sclerosis: expert panel consensus. J Neurol Sci 2007; 263(1-2): 3-14.

26 Kallenbach K, Frederiksen J. Optical coherence tomography in optic neuritis and multiple sclerosis: a review. Eur J Neurol 2007; 14(8): 841-849.

27 Ishikawa H, Stein DM, Wollstein G, Beaton S, Fujimoto JG, Schuman JS. Macular segmentation with optical coherence tomography. Invest Ophthalmol Vis Sci 2005; 46(6): 2012-2017.

28 Tan O, Li G, Lu AT, Varma R, Huang D, Advanced Imaging for Glaucoma Study Group. Mapping of macular substructures with optical coherence tomography for glaucoma diagnosis. Ophthalmology 2008; 115(6): 949-956.

29 Tan O, Chopra V, Lu AT, Schuman JS, Ishikawa H, Wollstein G et al. Detection of macular ganglion cell loss in glaucoma by Fourier-domain optical coherence tomography. Ophthalmology 2009; 116(12): 2305-2314.

30 Burkholder BM, Osborne B, Loguidice MJ, Bisker E, Frohman TC, Conger A et al. Macular volume determined by optical coherence tomography as a measure of neuronal loss in multiple sclerosis. Arch Neurol 2009; 66(11): 1366-1372.

31 Hirose T, Miyake Y, Hara A. Simultaneous recording of electroretinogram and visual evoked response. Focal stimulation under direct observation. Arch Ophthalmol 1977; 95(7): 1205-1208.

32 Miyake Y, Yanagida K, Kondo T, Yagasaki K. Simultaneous recording of local ERG and VER under direct fundus observation with infrared television fundus camera (author's transl). Nippon Ganka Gakkai Zasshi 1981; 85(10): 1521-1533.

33 Miyake Y, Awaya S. Stimulus deprivation amblyopia. Simultaneous recording of local macular electroretinogram and visual evoked response. Arch Ophthalmol 1984; 102(7): 998-1003.

34 Miyake Y. Studies of local macular ERG. Nippon Ganka Gakkai Zasshi 1988; 92(9): 1419-1449.

35 Miyake Y, Shiroyama N, Horiguchi M, Ota I. Asymmetry of focal ERG in human macular region. Invest Ophthalmol Vis Sci 1989; 30(8): 1743-1749. 
36 Miyake Y. Macular oscillatory potentials in humans. Macular OPs. Doc Ophthalmol 1990; 75(2): 111-124.

37 Hickman SJ, Toosy AT, Jones SJ, Altmann DR, Miszkiel KA MacManus DG et al. Serial magnetization transfer imaging in acute optic neuritis. Brain 2004; 127(Part 3): 692-700.

38 Smith KJ, McDonald WI. The pathophysiology of multiple sclerosis: the mechanisms underlying the production of symptoms and the natural history of the disease. Review. Philos Trans R Soc Lond B Biol Sci 1999; 354(1390): 1649-1673.

39 Jones SJ. Visual evoked potentials after optic neuritis. Effect of time interval, age and disease dissemination. J Neurol 1993; 240(8): 489-494.

40 Mafei L, Fiorentini A. Electroretinographic responses to alternating gratings before and after section of the optic nerve. Science 1981; 211(4485): 953-955.

41 Mafei L, Fiorentini A. Generator sources of the pattern ERG in man and animals. In: Gracco RQ, Bodis-Wollner I (eds). Frontiers in Clinical Neuroscience, 3rd Vol. Liss: New York, 1986, pp 101-106.
42 Kaufman DI, Lorance RW, Woods M, Wray SH. The pattern electroretinogram: a long-term study in acute optic neuropathy. Neurology 1988; 38(11): 1767-1774.

43 Berninger TA, Heider W. Electrophysiology and perimetry in acute retrobulbar neuritis. Doc Ophthalmol 1989; 71(3): 293-305.

44 Atilla H, Tekeli O, Ornek K, Batioglu F, Elhan AH, Eryilmaz T. Pattern electroretinography and visual evoked potentials in optic nerve diseases. J Clin Neurosci 2006; 13(1): 55-59.

45 Plant GT, Hess RF, Thomas SJ. The pattern evoked electroretinogram in optic neuritis. A combined psychophysical and electrophysiological study. Brain 1986; 109: $469-490$

46 Drasdo N, Cox W, Thompson DA. The effects of image degradation on retinal illuminance and pattern responses to checkerboard stimuli. Doc Ophthalmol 1987; 66(3): 267-275.

47 Holder GE. Significance of abnormal pattern electroretinography in anterior visual pathway dysfunction. Br J Ophthalmol 1987; 71(3): 166-171. 